\title{
Understanding the relationship between smartphone addiction and well- being: the mediation of mindfulness and moderation of hedonic Apps
}

\author{
Murad Moqbel \\ University of Texas Rio Grande Valley \\ murad.moqbel@utrgv.edu
}

\begin{abstract}
The advent of handheld devices such as smartphones has changed the way we connect, navigate, and entertain and has been recognized as a revolution in information and communication technologies (ICT). Despite the plethora of benefits of this new technology, concerns have been raised about the unintended adverse consequences to well-being in the form of addictive use. Past research has linked smartphone addiction to negative consequences, but it remains unclear how, why, and when (i.e., under what conditions) smartphone addiction, in turn, is related to well-being. This study attempts to fill this void by addressing these questions through the lens of the stimulus-organism-response framework. Theoretical and practical implications are discussed.
\end{abstract}

\section{Introduction}

The advent of handheld devices such as smartphones has changed the way we connect, navigate, and entertain and has been recognized as a revolution in information and communication technologies (ICT). Smartphones are an advanced version of mobile phones that enable access to the Internet for messaging, social media, viewing videos, and playing games. Smartphones are now very pervasive in everyday life with more than 2.5 billion users worldwide [1]. Alongside the plethora of beneficial uses of this pocket-size information bank, ranging from productivity enhancement (e.g., email, messaging, and calendar) [2], social support and social interaction (e.g., social media), information seeking (e.g., web browsing capabilities), health promotion (e.g., physical activity) [3], weight control [4, 5], obesity treatment [6], and communication, to GPS navigation and entertainment, concerns have been raised about the unintended consequences of addictive use that interfere with quality of life and well-being.

Excessive smartphone use has, perhaps, the potential to evolve into addictive behavior that is similar to gaming addiction, which has recently been officially recognized by the World Health Organization as a pathological addiction [7]. Although it is not officially recognized, the excessive use of smartphones has recently been demonstrated by researchers to be a behavioral addiction due to its resemblance to classical addiction symptoms including loss of control, withdrawal (anxiety when not using smartphones), tolerance (overuse of smartphones), relapse (unsuccessful attempts to reduce excessive use), mood modifications, salience, and negative influence on social and work lives [8-10]. The addictive use of smartphones can be easily observed in today's society. For individuals with smartphone addiction, the smartphone is the first thing they check as soon as they wake up and the last thing they look at before they go to bed. Also, one often sees couples who are out to dinner but glued to and constantly checking their smartphones throughout the meal, demonstrating the dominance of addictive smartphone use over social life.

In recent years, researchers have shown growing concern over smartphone addiction. Unlike prior studies, which assumed smartphone use to be positive for users $[2,11]$, other research efforts have begun to focus on the unintended negative consequences or dark side of smartphones. Researchers have highlighted these unintended negative consequences [12-14]; researched ways to measure their impact on individuals' mental health $[10,15-17]$; on leisure [18]; on academic performance [19]; and explored their antecedents [2022]. Yet, while recent research offers clear and comprehensive explanations of how smartphone addiction develops [23, 24] and leads to negative consequences [8-10], it remains unclear how, why, and when (i.e., under what conditions) smartphone addiction, in turn, relates to well-being. Absent understanding of the mechanisms linking smartphone addiction to negative outcomes, research can offer only limited practical guidance to individuals, managers, and healthcare practitioners on how to develop intervention strategies [25]. To provide a more comprehensive understanding of the implications of smartphone addiction for health and to provide improved practical guidance, research needs to generate a more 
sophisticated explanation of the factors that link smartphone addiction to well-being (i.e., mediation) and to highlight the contextual factors on which the influence on health depends (i.e., moderation). Therefore, this study attempts to offer a more comprehensive explanation of the interdependencies between smartphone addiction and other factors that explain in detail how and why smartphone addiction can relate to well-being (mediation) and when or under what conditions the influence on health augments (moderation).

To fully understand the relationship between smartphone addiction and well-being, we draw on the stimulus-organism-response (S-O-R) model [26, 27], which suggests that environmental factors (i.e., smartphone addictive use) serve as stimuli (S) that influence individual organisms (O) represented by emotive or cognitive states (e.g., mindfulness), which in turn lead to responses (R) (e.g., well-being-good health and technostress). Using the S-O-R model as a theoretical framework, we examine the relationship between smartphone addiction and well-being, the mediating effect of mindfulness, and the effect of smartphone addiction and technostress (stress due to ICTs) on health under hedonic (pleasure-oriented) usage conditions (moderation).

By investigating the interdependencies between smartphone addiction, mindfulness, and technostress in the prediction of well-being, we make important contributions. Our study helps research on technology addiction, smartphone addiction in particular, progress toward an enriched explanation of the process by which smartphone addiction relates to well-being. We posit that smartphone addiction is related to technostress and health not only directly but also indirectly. In addition, our study establishes certain smartphone usage conditions (hedonic vs. utilitarian) as contextual factors on which smartphone addiction and technostress negative effects on health depend. Overall, in this study, we generate an enhanced understanding of how, why, and when smartphone addiction relates to well-being.

The paper is organized as follows. The next section covers the theoretical lens that guides this study namely, the S-O-R paradigm that was developed by Mehrabian and Russell [26]. The following section presents the integrative model and hypotheses. Next, the research method will be described. Finally, we discuss the implications for information systems (IS) research and practice.

\section{Theoretical Foundations: Stimulus- Organism-Response Model}

The stimulus-organism-response model in environmental psychology [26] posits that environmental stimuli lead to an individual's emotive or cognitive reactions (i.e., internal states), which in turn evoke responses. The stimulus-organism-response model focuses on the reactions of the organism and the responses when the organism and the response are exposed to certain environmental stimuli. The organism represents internal emotive or cognitive states or processes that intervene between the stimuli and response. Therefore, this implies that internal emotive or cognitive states mediate the effect of stimuli on a response. Further, the response can be classified as either internally or externally detectable [27]. The S-O$\mathrm{R}$ model has been applied in various settings to explain the consumer-decision making process in online retail $[28,29]$, restaurants [30], and information disclosure [31].

We employ the S-O-R model as a theoretical lens to understand the formation of emotive and cognitive reactions of individuals and the relationship to health. In this study, the stimulus is smartphone addiction, the organism component includes the emotive and cognitive state of mindfulness, and the response is the level of well-being represented by technostress and health.

\section{Research Model}

Drawing from the literature, Figure 1 depicts our conceptualized theoretical research model and hypotheses. Our research model proposes that the smartphone addiction stimulus leads to cognitive and emotive reactions in the form of mindfulness, which, in turn, lead to a response in the form of a degree of wellbeing (technostress and health).

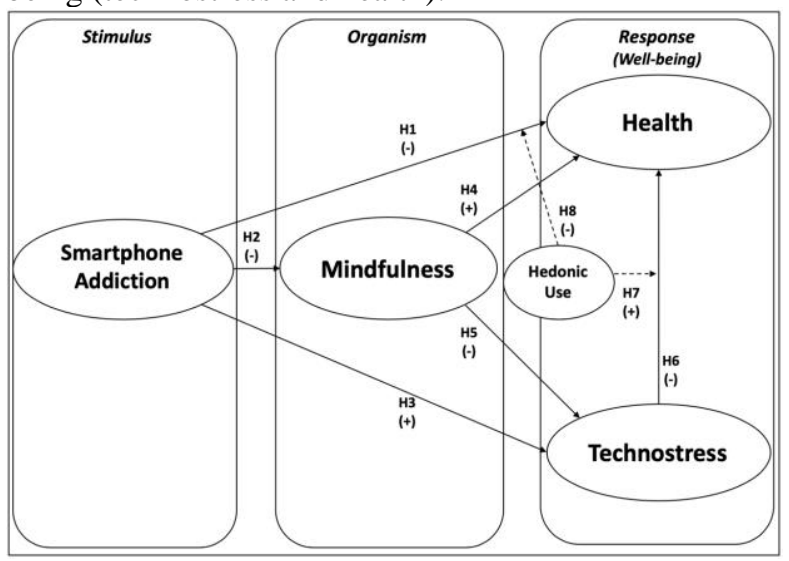

Figure 1. Research model with hypotheses

\subsection{Smartphone Addiction and Health}

Smartphone addiction is one of several types of behavioral addictions. The term "addiction" initially was used to refer to a condition in which an individual has a heavy dependence on a substance (e.g., drugs) or 
an activity (e.g., gambling) [32]. Dependence, however, refers to overindulgence, craving, withdrawal, tolerance, and loss of control [33]. Despite originally being associated with substance use, there is an increasing recognition of the broad range of conditions that define addiction that involve not only the ingestion of substances but also the excessive engagement in a behavior (i.e., behavioral addiction) leading to negligence of one's life responsibilities (such as health, work, and relationships) $[34,35]$. Scholars have studied various types of such behavioral addictions including gambling [36], eating disorders [37], TV addiction [38], and technology addictions such as video gaming [7], cyber disorders [39], computer addiction [40], Internet addiction [41-44], Internet gambling addiction [45], compulsive Internet use [46], Internet gaming addiction [47], online auction addiction [48], mobile phone addiction [49, 50], Internet sex addiction [51], social network site addiction [35, 52], and smartphone addiction [8-10]. Current research characterizes a behavioral addiction diagnosis as the existence of functional impairments in social relationships, at work, or in other social situations [53, 54]. Although there is no agreement on a definition of addiction, the consensus among most researchers is that technology addiction incorporates psychological dependence on the use of technology [35, 48, 55]. Among the different types of technology addictions, smartphone addiction is prevalent in our society today.

We define health in this paper as perceived physical and mental health over time. Smartphone addiction influences mental health in various ways. Addictive smartphone use causes mental health symptoms such as stress primarily due to the perception of having to be accessible at all hours, even during nighttime [17]. Prolonged use of technology has also been associated with increased psychological distress [56]. The health literature determined that there is a link between the electromagnetic radiation from smartphones and changes in the antioxidant defense systems of human tissues that, in turn, causes oxidative stress [57]. A more recent study explained the underlying biological mechanisms through which mental health is impacted by smartphone addiction [58], indicating that smartphone addiction raises the levels of a neurotransmitter called GABA in the brain that inhibits brain signal leading to mental health issues such as anxiety. Therefore, smartphone addiction affects mental health for psychological and biological reasons.

Smartphone addiction affects physical health as well. For example, the time spent on smartphones is more likely to be spent indoors inducing a sedentary lifestyle. In other words, screen time on smartphones is replacing time that individuals should be spending on physical, social, or intellectual activities, that are vital to healthy development.

Given the high level of stimuli in the form of smartphone addiction that individuals experience, we expect that the response will be poor physical and mental health. Hence,

Hypothesis 1: There is a negative relationship between the extent of smartphone addiction and health.

\subsection{Smartphone Addiction and Mindfulness}

The mindfulness concept, which is rooted in the Buddhist tradition, is defined as "receptive attention to awareness of the present events and experience" [59]. In other words, mindfulness is entrenched in conscious behaviors-attention and awareness. Mindlessness, the opposite of mindfulness, is characterized by doing tasks automatically without being aware of or attentive to what is being done [60].

There is growing interest in the IS field in mindfulness [61]. Mindfulness has been studied mainly at the organizational level $[62,63]$. For example, Butler and Gray [64] suggested fundamental ways in which organizations can mindfully benefit from information technologies to achieve reliable performance. There is minimal research studying mindfulness at the individual level [e.g., 61]; however such research efforts are pivotal. Since mindfulness is considered to be a cognitive-emotive regulation strategy [65], we use mindfulness in this study as an organism (i.e., cognitiveemotive state) resulting from the stimulus (i.e., smartphone addiction) in the S-O-R model

In this research, we argue that smartphone addiction can lead to lower mindfulness. The reason is that when individuals are addicted to their smartphones, they lose awareness of their actions at the present moment because of smartphone-use-urge distraction. This absence of awareness and attention (mindlessness) behavior is manifested in society today. For example, pedestrians are seen bumping into others or triping over obstacles while walking down the street because they are using their smartphones without paying attention to their surroundings. Also, individuals addicted to smartphones tend to lack concentration because of the constant distraction they experience from attentionswitching. Research has documented that individuals who frequently switch attention were less likely to be able to sustain attention and perform well [66]. This distraction increases even more because of the multitasking behavior individuals with smartphone addiction develop when using multiple apps simultaneously and switching their attention from one social media app to another, and task-switching behavior has been linked to reduced attention [67]. Therefore, these behaviors reduce the mindfulness of 
individuals with smartphone addiction. Hence, based on the S-O-R model, we expect the reaction of an organism when exposed to a stimulus (smartphone addiction) to be an emotive-cognitive state of low mindfulness. Accordingly, we advance the following hypothesis:

Hypothesis 2: There is a negative relationship between the extent of smartphone addiction and mindfulness.

\subsection{Smartphone Addiction and Technostress}

The technostress concept was first introduced by psychologist Craig Brod who defined it as "a modern disease of adaptation caused by an inability to cope with the new computer technologies in a healthy manner" [68]. The definition of technostress was expanded to include "any negative impact on attitudes, thoughts, behaviors, or body psychology caused directly or indirectly by technology" [69]. We, therefore, incorporate technostress in this study to pinpoint stress related to smartphone usage.

Addicted users of technology such as smartphones tend to experience difficulty controlling time [35, 50, $54,70]$ and decrease personal contacts in real life, resulting in social isolation that, in turn, leads to stress [71]. Tolerance symptoms of technology addiction increase the severity of stress [72]. Addicted users to smartphones exhibit the following: (1) negligence of important things because of interest in their phones; (2) risk to their social lives because of interaction with phones, (3) interference of phone use with other activities; (4) feeling agitated when not using their phone, (4) making unsuccessful attempts to reduce the time they interact with their phones, (5) being late for engagements because of their phone interactions; (6) arguments at home because of the time they spend on their phones, (7) failure to get enough rest because of their addictive use of phone. When the addictive behavior signs above are perceived to be inescapable, negative consequences of psychological distress such as stress are more likely to be augmented as well [73]. In this study, technostress is used as an indicator of stress. Thus, we propose, based on the S-O-R model, that the addictive use of smartphones (stimulus) leads to a response in the form of technostress. Based on this we state the following:

Hypothesis 3: There is a positive relationship between the extent of smartphone addiction and technostress.

\subsection{Mindfulness and Well-Being}

Mindfulness is commonly defined as the quality of awareness or consciousness that results from intentionally attending with non-judgementalness and openness to present-moment experiences [74]. Mindfulness theory, a subdivision of positive psychology and the science of well-being and strengths [75], emphasizes awareness of the context in the present moment [76], which enables individuals to be sensitive to an environment that supports clearer thoughts and behaviors [77]. Moreover, there is evidence that mindfulness can affect health and well-being [78, 79].

Several models have explained the mechanisms of how mindfulness affects well-being [59, 80-84]. The majority of these models seem to agree on the importance of the 'decentering' concept, which refers to the ability to "step outside one's immediate experience, thereby changing the very nature of that experience" [85]. One of these seminal models is the reperceiving model in which Shapiro, Carlson, Astin and Freedman [83]) postulate that the process of mindfulness (intentionally attending with openness and nonjudgmentalness) causes reperceiving. Similar to the deautomatization concept, which refers to "undoing of the automatic processes that control perception and cognition" [86], reperceiving refers to the ability to disidentify from one's thoughts and view his or her experience with better objectivity and clarity. In particular, this fundamental shift in perspective is facilitated by the mindfulness process [83] and leads to increased openness toward unwanted personal experiences and positive emotions. In summary, all of these models seem to conclude that the goal of mindfulness is to sustain awareness and disengage oneself from attachment to thoughts, beliefs, or emotions, thereby cultivating a better sense of emotional balance and well-being [87].

Evidence from neurobiological and behavioral laboratory studies indicates that mindfulness practices show promise in reducing mental health symptoms and enhancing well-being [88, 89]. There is evidence that mindfulness practices benefited individuals diagnosed with mental health issues including anxiety [90, 91], anger [90], depression [90, 92, 93], rumination [90, 94], cognitive disorganization [93], general psychological distress [93, 95], and post-traumatic symptoms [95].

Mindfulness was also found to have a positive relationship with well-being [96] and indicators of psychological health such as higher levels of positive emotions, vitality, life satisfaction, and adaptive emotion regulation and lower levels of negative emotions and psychopathological symptoms [78]. Similarly, we posit that mindfulness improves health and reduces technostress and thus can contribute greatly to an individual's well-being. Based on the S-O-R model, we posit the following:

Hypothesis 4: There is a positive relationship between mindfulness and health. 
Hypothesis 5: There is a negative relationship between mindfulness and technostress.

\subsection{Technostress and Well-Being}

We propose that individuals with high levels of technostress symptoms will experience a lowered sense of well-being. Technostress leads to decreasing wellness, especially for those who use technology excessively (e.g., smartphones) and who can be described as having "stress immobility syndrome" [97]. This syndrome occurs when individuals use technology (e.g., smartphones) while stressed and sedentary for prolonged periods, resulting in illness. Technostress is also characterized by signs of obsessive use of smartphones that in turn lead to harmful physical and mental health symptoms including cardiovascular, gastrointestinal, and insomnia disorders, chronic fatigue, irritability, depression, decreased sexual desire, and behavioral changes [98]. In addition, a higher level of stress (e.g., technostress) generates the cortisol hormone, which impedes the immune, digestive, and reproductive systems and impacts both mental and physical health negatively [99]. Accordingly, we posit that individuals with high levels of technostress will experience poor mental and physical health. Hence,

Hypothesis 6: There is a negative relationship between technostress and health.

\subsection{Hedonic Smartphone Use as A Moderating Effect}

We also propose that the type of smartphone use will buffer the relationship between technostress and health. Information systems have been classified in the IS literature as hedonic and utilitarian [100]. Hedonic information systems refer to systems that afford selffulfilling value to the user, are related to leisure activities, focus on the fun side of use, and stimulate prolonged use [100]. Smartphones can be used as both hedonic systems-offering self-fulfilling value of enjoyment and leisure (e.g., social media and games)and utilitarian systems-affording instrumental value and productive use (e.g., email, reading, and communicating). We posit that hedonic use of smartphones buffers the adverse effect of technostress on health because the fun and leisure aspects of phone use (e.g., social media) will modify the impact of technostress on health. In fact, scholars have dedicated considerable attention to coping resources that can buffer the health effects of exposure to stress [101]. When managing strains (e.g., technostress), people draw on several personal and social assets. One example of such stress-buffers is social support, which refers to informational, emotional, or practical assistance from others such as friends, family members, or coworkers [102]. Social support reduces stress-related psychological distress and physiological arousal [103, 104]. Research has documented that hedonic information systems such as social networking sites are a source of social support from family members, coworkers, and friends that can help individuals cope with stress and augment positive outcomes including worklife balance $[105,106]$. Hence, based on the buffering hypothesis theory [107], which posits that social support systems (e.g., social networks available through social media apps) shield an individual from or buffer the negative impact of stressful events (technostress) and enhance an individual's longevity and health, we conclude that the hedonic use of smartphones will buffer (weaken) the negative relationship between technostress and health. Therefore, we put forward the following hypothesis:

Hypothesis 7: Hedonic use of smartphones weakens the negative relationship between technostress and health.

Hedonic information systems are characterized by their prolonged use [100]. This extended use of hedonic information systems/apps in smartphones, in turn, induces higher levels of smartphone addiction. When individuals experience enjoyment or pleasure from using an information system, they are likely to use it more [100, 108, 109]. In fact, the hedonic-use aspect of digital artifacts (e.g., enjoyment) has been found to be a pivotal determinant in increasing IS usage [109-111]. Therefore, we posit that hedonic use of smartphones fuels smartphone addiction, strengthening the adverse effect of smartphone addiction on health. Based on this we state the following:

Hypothesis 8: Hedonic use of smartphones strengthens the negative relationship between smartphone addiction and health.

\subsection{Mindfulness as A Mediator}

In considering the effects of smartphone addiction on health, there is still an important question worth investigating: how and why smartphone addiction is related to health. Is there a causal pathway through which smartphone addiction affects well-being?

On the one hand, mindfulness has been directly associated with well-being and mental health [95, 112]. For example, mindfulness has been demonstrated to reduce mental health problems such as anxiety, depression, negative emotions, and loneliness [113, 114] and increase well-being in self-esteem, life satisfaction, and positive emotions [114]. Moreover, researchers have reported a relationship between technology addiction and mindfulness, for example, social media addiction negatively impacts mindfulness 
[115]. Further, because individuals with higher levels of mindfulness utilize more adaptive coping strategies when faced with stressful events [114], these positive coping strategies enable them to modify the relationship with their addictive behavior and enhance their wellbeing [116]. In other words, mindfulness helps augment coping mechanisms by mediating the relationship between addictive use of a smartphone and health.

According to the above discussion, increased smartphone addiction would reduce the user's mindfulness, and mindfulness also plays a critical role in enhancing well-being. Based on the S-O-R model, it is reasonable to assume that mindfulness is an emotivecognitive mechanism (organism) underlying the link between smartphone addiction (stimulus) and wellbeing (response). Thus, we hypothesize that mindfulness plays a mediating role in the relationship between smartphone addiction and well-being.

Hypothesis 9: Smartphone addiction influences technostress through the mediating role of mindfulness.

Hypothesis 10: Smartphone addiction influences health through the mediating role of mindfulness

\section{Research Methodology}

We will collect data via an online survey from students at a large university in the Midwest region of the United States after gaining an exempt approval from the institutional review board (no identifiable data are collected). Validated measurement scales will be adopted from the literature. Study participation will occur as a two-part process where students will be required to download a free app on their smartphone device for seven days and complete a survey at the conclusion of the seventh day. The app tracks the amount of time the study participant spends on their phone in addition to the number of times the phone is accessed each day. The app delineates access based upon each instance when a user opens the home screen on the device. Participants with Apple devices will download the Moment App (2016) while Android device users will download the QualityTime App. Emails regarding the study details will be distributed to students. In addition to email communication, classroom visits will be conducted to describe the specifications of the study. Reminder emails will be sent to students one week following the initial email or classroom visit which will include a link to the survey and directions on how to complete the survey. In addition, we will provide participants with directions on how to report app usage through their phone battery usage/screen time so that we can measure the hedonic/social use vs. the utilitarian/functional use of their phone apps.
Smartphone addiction was measured using items adapted from Moqbel and Kock [35] and Charlton [54]. Mindfulness was adopted from Black, Sussman, Johnson and Milam [60]. Technostress was measured by scales from Ayyagari, Grover and Purvis [117] and Moore [118]. Health was measured by scales after Moriarty, Zack and Kobau [119] and Moqbel and Kock [35].

PLS-based structural equation modeling will be employed as the data analysis method for this study. The WarpPLS 6.0 will be used to analyze the data.

\section{Expected Contributions}

Investigating the interdependencies between smartphone addiction, mindfulness, and technostress in the prediction of well-being will make important contributions. Our study helps research on technology addiction, smartphone addiction in particular, progress toward an enriched explanation of the process by which smartphone addiction relates to well-being. Absent understanding of the mechanisms linking smartphone addiction to negative outcomes, research can offer only limited practical guidance to individuals, managers, and healthcare practitioners on how to develop intervention strategies. To provide a more comprehensive understanding of the implications of smartphone addiction for health and to provide improved practical guidance, research needs to generate a more sophisticated explanation of the factors that link smartphone addiction to well-being (i.e., mediation) and to highlight the contextual factors on which the influence on health depends (i.e., moderation). Therefore, this study attempts to offer a more comprehensive explanation of the interdependencies between smartphone addiction and other factors that explain in detail how and why smartphone addiction is related to well-being (mediation) and when or under what conditions this relationship augments (moderation).

One limitation of this study that future research should be aware of is that smartphone addiction can be an internal stimulus rather than an external stimulus. Therefore, other models than the S-O-R model can better fit this research. Future studies should focus on addiction to applications on the smartphone rather than on addiction to the smartphone itself because people get addicted to the use of the applications inside the smartphone. Future research should also consider other moderated relationships such as utilitarian apps.

We posit that smartphone addiction is related to technostress and health not only directly but also indirectly through the mediation of mindfulness. In addition, our study establishes certain smartphone usage conditions (hedonic vs. utilitarian) as contextual factors 
on which smartphone addiction and technostress negative effects on health depend. Overall, in this study,

\section{References}

[1] Statista: 'Smartphone users worldwide 2014-2020' (Statista, 2018. 2018)

[2] Kim, H., Lee, M., and Kim, M.: 'Effects of mobile instant messaging on collaborative learning processes and outcomes: The case of South Korea', Journal of Educational Technology \& Society, 2014, 17, (2), pp. 31 [3] Benson, A.C., Bruce, L., and Gordon, B.A.: 'Reliability and validity of a GPS-enabled iPhoneTM "app" to measure physical activity', Journal of sports sciences, 2015, 33, (14), pp. 1421-1428

[4] Mameli, C., Brunetti, D., Colombo, V., Bedogni, G., Schneider, L., Penagini, F., Borsani, B., and Zuccotti, G.: 'Combined use of a wristband and a smartphone to reduce body weight in obese children: randomized controlled trial', Pediatric obesity, 2018, 13, (2), pp. 81-87

[5] Pellegrini, C.A., Duncan, J.M., Moller, A.C., Buscemi, J., Sularz, A., DeMott, A., Pictor, A., Pagoto, S., Siddique, J., and Spring, B.: 'A smartphone-supported weight loss program: design of the ENGAGED randomized controlled trial', BMC public health, 2012, 12, (1), pp. 1041

[6] O’Malley, G., Clarke, M., Burls, A., Murphy, S., Murphy, N., and Perry, I.J.: 'A smartphone intervention for adolescent obesity: study protocol for a randomised controlled non-inferiority trial', Trials, 2014, 15, (1), pp. 43 [7] Healy, M.: 'World Health Organization says video game addiction is a disease. Why American psychiatrists don't', in Editor (Ed.)^(Eds.): 'Book World Health Organization says video game addiction is a disease. Why American psychiatrists don't' (2018, edn.), pp. [8] Lin, Y.-H., Lin, Y.-C., Lee, Y.-H., Lin, P.-H., Lin, S.H., Chang, L.-R., Tseng, H.-W., Yen, L.-Y., Yang, C.C., and Kuo, T.B.: 'Time distortion associated with smartphone addiction: Identifying smartphone addiction via a mobile application (App)', Journal of psychiatric research, 2015, 65, pp. 139-145

[9] Kwon, M., Kim, D.-J., Cho, H., and Yang, S.: 'The smartphone addiction scale: development and validation of a short version for adolescents', PloS one, 2013, 8, (12), pp. e83558

[10] Samaha, M., and Hawi, N.S.: 'Relationships among smartphone addiction, stress, academic performance, and satisfaction with life', Computers in Human Behavior, 2016, 57, pp. 321-325

[11] Auter, P.J.: 'Portable social groups: willingness to communicate, interpersonal communication gratifications, and cell phone use among young adults', International Journal of Mobile Communications, 2006, 5, (2), pp. 139156

[12] Park, C., and Park, Y.R.: 'The conceptual model on smart phone addiction among early childhood', International Journal of Social Science and Humanity, 2014, 4, (2), pp. 147

[13] Billieux, J., Maurage, P., Lopez-Fernandez, O., Kuss, D.J., and Griffiths, M.D.: 'Can disordered mobile phone use be considered a behavioral addiction? An update on we generate an enhanced understanding of how, why, and when smartphone addiction is related to well-being. current evidence and a comprehensive model for future research', Curr Addict Rep, 2015, 2, (2), pp. 156-162 [14] Billieux, J.: 'Problematic use of the mobile phone: a literature review and a pathways model', Current Psychiatry Reviews, 2012, 8, (4), pp. 299-307 [15] Çağan, Ö., Ünsal, A., and Çelik, N.: 'Evaluation of college students' the level of addiction to cellular phone and investigation on the relationsship between the addiction and the level of depression', Procedia-Social and Behavioral Sciences, 2014, 114, pp. 831-839

[16] Elhai, J.D., Dvorak, R.D., Levine, J.C., and Hall, B.J.: 'Problematic smartphone use: A conceptual overview and systematic review of relations with anxiety and depression psychopathology', Journal of affective disorders, 2017, 207, pp. 251-259

[17] Thomée, S., Härenstam, A., and Hagberg, M.: 'Mobile phone use and stress, sleep disturbances, and symptoms of depression among young adults-a prospective cohort study', BMC public health, 2011, 11, (1), pp. 66 [18] Lepp, A., Li, J., Barkley, J.E., and Salehi-Esfahani, S.: 'Exploring the relationships between college students' cell phone use, personality and leisure', Computers in human behavior, 2015, 43, pp. 210-219

[19] Lepp, A., Barkley, J.E., and Karpinski, A.C.: 'The relationship between cell phone use, academic performance, anxiety, and satisfaction with life in college students', Computers in Human Behavior, 2014, 31, pp. 343-350

[20] Hong, F.-Y., Chiu, S.-I., and Huang, D.-H.: 'A model of the relationship between psychological characteristics, mobile phone addiction and use of mobile phones by Taiwanese university female students', Computers in Human Behavior, 2012, 28, (6), pp. 2152-2159

[21] Walsh, S.P., White, K.M., Cox, S., and Young, R.M.: 'Keeping in constant touch: The predictors of young Australians' mobile phone involvement', Computers in Human Behavior, 2011, 27, (1), pp. 333-342

[22] Chiu, S.-I.: 'The relationship between life stress and smartphone addiction on Taiwanese university student: A mediation model of learning self-efficacy and social selfefficacy', Computers in human behavior, 2014, 34, pp. 4957

[23] Van Deursen, A.J., Bolle, C.L., Hegner, S.M., and Kommers, P.A.: 'Modeling habitual and addictive smartphone behavior: The role of smartphone usage types, emotional intelligence, social stress, self-regulation, age, and gender', Computers in human behavior, 2015, 45, pp. 411-420

[24] Wang, J.-L., Wang, H.-Z., Gaskin, J., and Wang, L.H.: 'The role of stress and motivation in problematic smartphone use among college students', Computers in Human Behavior, 2015, 53, pp. 181-188

[25] MacKinnon, D.P., and Luecken, L.J.: 'How and for whom? Mediation and moderation in health psychology', Health psychology, 2008, 27, (2S), pp. 1-4

[26] Mehrabian, A., and Russell, J.A.: 'An approach to environmental psychology’ (The MIT Press, 1974. 1974) 
[27] Jacoby, J.: 'Stimulus-organism-response reconsidered: an evolutionary step in modeling (consumer) behavior', Journal of Consumer Psychology, 2002, 12, (1), pp. 51-57 [28] Kim, J., and Lennon, S.J.: 'Effects of reputation and website quality on online consumers' emotion, perceived risk and purchase intention: Based on the stimulusorganism-response model', Journal of Research in Interactive Marketing, 2013, 7, (1), pp. 33-56 [29] Wang, Y.J., Minor, M.S., and Wei, J.: 'Aesthetics and the online shopping environment: Understanding consumer responses', Journal of Retailing, 2011, 87, (1), pp. 46-58 [30] Jang, S.S., and Namkung, Y.: 'Perceived quality, emotions, and behavioral intentions: Application of an extended Mehrabian-Russell model to restaurants', Journal of Business Research, 2009, 62, (4), pp. 451-460 [31] Li, H., Sarathy, R., and Xu, H.: 'The role of affect and cognition on online consumers' decision to disclose personal information to unfamiliar online vendors', Decision Support Systems, 2011, 51, (3), pp. 434-445 [32] Widyanto, L., and McMurran, M.: 'The psychometric properties of the internet addiction test', Cyberpsychology \& behavior, 2004, 7, (4), pp. 443-450

[33] APA, A.P.A.: 'Diagnostic and Statistical Manual of Mental Disorders (DSM)' (American Psychiatric Association, 1994. 1994)

[34] Lemon, J.: 'Can we call behaviours addictive?', Clinical psychologist, 2002, 6, (2), pp. 44-49

[35] Moqbel, M., and Kock, N.: 'Unveiling the dark side of social networking sites: Personal and work-related consequences of social networking site addiction', Information \& Management, 2018, 55, (1), pp. 109-119

[36] Griffiths, M.D.: 'The cognitive psychology of gambling', Journal of gambling studies, 1990, 6, (1), pp. $31-42$

[37] Lesieur, H.R., and Blume, S.B.: 'Pathological gambling, eating disorders, and the psychoactive substance use disorders', Journal of Addictive diseases, 1993, 12, (3), pp. $89-102$

[38] Horvath, C.W.: 'Measuring television addiction', Journal of Broadcasting \& Electronic Media, 2004, 48, (3), pp. 378-398

[39] Young, K., Pistner, M., O'MARA, J., and Buchanan,

J.: 'Cyber disorders: The mental health concern for the new millennium', CyberPsychology \& Behavior, 1999, 2, (5), pp. 475-479

[40] Shotton, M.A.: 'The costs and benefits of 'computer addiction', Behaviour \& Information Technology, 1991, 10, (3), pp. 219-230

[41] Beard, K.W.: 'Internet addiction: a review of current assessment techniques and potential assessment questions', CyberPsychology \& Behavior, 2005, 8, (1), pp. 7-14

[42] Yang, S.C., and Tung, C.-J.: 'Comparison of Internet addicts and non-addicts in Taiwanese high school', Computers in Human Behavior, 2007, 23, (1), pp. 79-96 [43] Young, K.S.: 'Psychology of computer use: XL. Addictive use of the Internet: a case that breaks the stereotype', Psychological Reports, 1996, 79, (3), pp. 899902

[44] Young, K.S., and de Abreu, C.N.: 'Internet addiction: A handbook and guide to evaluation and treatment' (John Wiley \& Sons, 2010. 2010)
[45] Kuss, D., and Griffiths, M.: 'Internet gambling behavior' (IGI Global, 2011. 2011)

[46] Meerkerk, G.-J., Van Den Eijnden, R.J., Vermulst, A.A., and Garretsen, H.F.: 'The compulsive internet use scale (CIUS): some psychometric properties', CyberPsychology \& Behavior, 2009, 12, (1), pp. 1-6 [47] Kuss, D.J., and Griffiths, M.D.: 'Internet gaming addiction: A systematic review of empirical research', International Journal of Mental Health and Addiction, 2012, 10, (2), pp. 278-296

[48] Turel, O., Serenko, A., and Giles, P.: 'Integrating technology addiction and use: An empirical investigation of online auction users', MIS Quarterly, 2011, 35, (4), pp. 1043-1062

[49] Choliz, M.: 'Mobile phone addiction: a point of issue', Addiction, 2010, 105, (2), pp. 373-374

[50] Turel, O., Serenko, A., and Bontis, N.: 'Family and work-related consequences of addiction to organizational pervasive technologies', Information \& Management, 2011, 48, (2), pp. $88-95$

[51] Griffiths, M.D.: 'Internet sex addiction: A review of empirical research', Addiction Research \& Theory, 2012, 20, (2), pp. 111-124

[52] Kuss, D.J., and Griffiths, M.D.: 'Online social networking and addiction - a review of the psychological literature', International Journal of Environmental Research and Public Health, 2011, 8, (9), pp. 3528-3552

[53] Widyanto, L., and Griffiths, M.: 'Internet Addiction': A Critical Review', International Journal of Mental Health and Addiction, 2006, 4, (1), pp. 31-51

[54] Charlton, J.P.: 'A factor-analytic investigation of computer 'addiction' and engagement', British Journal of Psychology, 2002, 93, (3), pp. 329-344

[55] Serenko, A., and Turel, O.: 'Integrating Technology Addiction and Use: An Empirical Investigation of Facebook Users', AIS Transactions on Replication Research (Forthcoming), 2015, pp. 1-14

[56] Chesley, N.: 'Blurring boundaries? Linking technology use, spillover, individual distress, and family satisfaction', Journal of Marriage and Family, 2005, 67, (5), pp. 1237-1248

[57] Ozguner, F., Altinbas, A., Ozaydin, M., Dogan, A., Vural, H., Kisioglu, A.N., Cesur, G., and Yildirim, N.G.: 'Mobile phone-induced myocardial oxidative stress: protection by a novel antioxidant agent caffeic acid phenethyl ester', Toxicology and industrial health, 2005, 21, (7-8), pp. 223-230

[58] Seo, H.S., Jeong, E.-K., Choi, S., Kwon, Y., Park, H.J., and Kim, I.: 'Neurotransmitters in young people with internet and smartphone addiction: a comparison with normal controls and changes after cognitive behavioral therapy', in Editor (Ed.)^(Eds.): 'Book Neurotransmitters in young people with internet and smartphone addiction: a comparison with normal controls and changes after cognitive behavioral therapy' (Radiological Society of North America, 2017, edn.), pp.

[59] Brown, K.W., Ryan, R.M., and Creswell, J.D.:

'Mindfulness: Theoretical foundations and evidence for its salutary effects', Psychological inquiry, 2007, 18, (4), pp. 211-237 
[60] Black, D.S., Sussman, S., Johnson, C.A., and Milam, J.: 'Psychometric assessment of the mindful attention awareness scale (MAAS) among Chinese adolescents', Assessment, 2012, 19, (1), pp. 42-52

[61] Sun, H., and Fang, Y.: 'Choosing a fit technology: Understanding mindfulness in technology adoption and continuance', Journal of the Association for Information Systems, 2016, 17, (6), pp. 377

[62] Fichman, R.G.: 'Going beyond the dominant paradigm for information technology innovation research: Emerging concepts and methods', Journal of the association for information systems, 2004, 5, (8), pp. 11

[63] Swanson, E.B., and Ramiller, N.C.: 'Innovating mindfully with information technology', MIS quarterly, 2004, pp. 553-583

[64] Butler, B.S., and Gray, P.H.: 'Reliability, mindfulness, and information systems', Mis Quarterly, 2006, pp. 211224

[65] Martos, M.P.B., Lopez-Zafra, E., Pulido-Martos, M., and Augusto, J.M.: 'Are emotional intelligent workers also more empathic?', Scandinavian journal of psychology, 2013, 54, (5), pp. 407-414

[66] Ophir, E., Nass, C., and Wagner, A.D.: 'Cognitive control in media multitaskers', Proceedings of the National Academy of Sciences, 2009, 106, (37), pp. 15583-15587

[67] Rosen, L.D., Carrier, L.M., and Cheever, N.A.: 'Facebook and texting made me do it: Media-induced taskswitching while studying', Computers in Human Behavior, 2013, 29, (3), pp. 948-958

[68] Brod, C.: 'Technostress: The human cost of the computer revolution' (Addison Wesley Publishing Company, 1984. 1984)

[69] Weil, M., and Rosen, L.: 'Technostress: Coping with technology@work@ home@ play', in Editor (Ed.) $)^{\wedge}($ Eds.): 'Book Technostress: Coping with technology@work@ home@ play’ (Wiley, 1997, edn.),pp.

[70] Tarafdar, M., Pullins, E.B., and Ragu-Nathan, T.: 'Technostress: negative effect on performance and possible mitigations', Information Systems Journal, 2015, 25, (2), pp. 103-132

[71] Kumar, S.: 'Mobile phone and adolescents-addiction a mindful check in', International Journal of Advanced Nursing Studies, 2014, 3, (1), pp. 42-46

[72] Ko, C.: 'The effects of addictive cell-phone use of adolescence on mental health', Forum For Youth Culture, 2012, 30, pp. 8-36

[73] Matusik, S.F., and Mickel, A.E.: 'Embracing or embattled by converged mobile devices? Users'

experiences with a contemporary connectivity technology', Human Relations, 2011, 64, (8), pp. 1001-1030

[74] Kabat-Zinn, J.: 'Wherever you go, there you are: mindfulness meditation in everyday life' (Hyperion Books, 1994. 1994)

[75] Ivtzan, I., and Lomas, T.: 'Mindfulness in positive psychology: The science of meditation and wellbeing' (Routledge, 2016. 2016)

[76] Langer, E.J.: 'Langer mindfulness scale user guide and technical manual' ( IDS, 2004. 2004)

[77] Demick, J.: 'Toward a mindful psychological science: Theory and application', Journal of Social Issues, 2000, 56, (1), pp. 141-159
[78] Keng, S.-L., Smoski, M.J., and Robins, C.J.: 'Effects of mindfulness on psychological health: A review of empirical studies', Clinical psychology review, 2011, 31, (6), pp. 1041-1056

[79] Janssen, M., Heerkens, Y., Kuijer, W., Van Der Heijden, B., and Engels, J.: 'Effects of Mindfulness-Based Stress Reduction on employees' mental health: A systematic review', PloS one, 2018, 13, (1), pp. e0191332 [80] Baer, R.A.: 'Mindfulness training as a clinical intervention: A conceptual and empirical review', Clinical psychology: Science and practice, 2003, 10, (2), pp. 125143 [81] Grabovac, A.D., Lau, M.A., and Willett, B.R.: 'Mechanisms of mindfulness: A Buddhist psychological model', Mindfulness, 2011, 2, (3), pp. 154-166

[82] Hölzel, B.K., Lazar, S.W., Gard, T., Schuman-Olivier, Z., Vago, D.R., and Ott, U.: 'How does mindfulness meditation work? Proposing mechanisms of action from a conceptual and neural perspective', Perspectives on psychological science, 2011, 6, (6), pp. 537-559 [83] Shapiro, S.L., Carlson, L.E., Astin, J.A., and Freedman, B.: 'Mechanisms of mindfulness', Journal of clinical psychology, 2006, 62, (3), pp. 373-386

[84] Vago, D.R., and David, S.A.: 'Self-awareness, selfregulation, and self-transcendence (S-ART): a framework for understanding the neurobiological mechanisms of mindfulness', Frontiers in human neuroscience, 2012, 6, pp. 296

[85] Safran, J., and Segal, Z.: 'Cognitive therapy: An interpersonal process perspective', New York: Basic, 1990 [86] Deikman, A.J.: 'The observing self: Mysticism and psychotherapy' (Beacon Press, 1982. 1982)

[87] Ludwig, D.S., and Kabat-Zinn, J.: 'Mindfulness in medicine', Jama, 2008, 300, (11), pp. 1350-1352

[88] Creswell, J.D., Way, B.M., Eisenberger, N.I., and Lieberman, M.D.: 'Neural correlates of dispositional mindfulness during affect labeling', Psychosomatic medicine, 2007, 69, (6), pp. 560-565

[89] Way, B.M., Creswell, J.D., Eisenberger, N.I., and Lieberman, M.D.: 'Dispositional mindfulness and depressive symptomatology: Correlations with limbic and self-referential neural activity during rest', Emotion, 2010, 10, (1), pp. 12

[90] Anderson, N.D., Lau, M.A., Segal, Z.V., and Bishop, S.R.: 'Mindfulness-based stress reduction and attentional control', Clinical Psychology \& Psychotherapy: An International Journal of Theory \& Practice, 2007, 14, (6), pp. 449-463

[91] Shapiro, S.L., Schwartz, G.E., and Bonner, G.: 'Effects of mindfulness-based stress reduction on medical and premedical students', Journal of behavioral medicine, 1998, 21, (6), pp. 581-599

[92] Grossman, P., Kappos, L., Gensicke, H., D'Souza, M., Mohr, D.C., Penner, I.K., and Steiner, C.: 'MS quality of life, depression, and fatigue improve after mindfulness training A randomized trial', Neurology, 2010, 75, (13), pp. 1141-1149

[93] Speca, M., Carlson, L.E., Goodey, E., and Angen, M.: 'A randomized, wait-list controlled clinical trial: the effect of a mindfulness meditation-based stress reduction program 
on mood and symptoms of stress in cancer outpatients', Psychosomatic medicine, 2000, 62, (5), pp. 613-622 [94] Jain, S., Shapiro, S.L., Swanick, S., Roesch, S.C., Mills, P.J., Bell, I., and Schwartz, G.E.: 'A randomized controlled trial of mindfulness meditation versus relaxation training: effects on distress, positive states of mind, rumination, and distraction', Annals of behavioral medicine, 2007, 33, (1), pp. 11-21

[95] Bränström, R., Kvillemo, P., Brandberg, Y., and Moskowitz, J.T.: 'Self-report mindfulness as a mediator of psychological well-being in a stress reduction intervention for cancer patients-A randomized study', Annals of behavioral medicine, 2010, 39, (2), pp. 151-161

[96] Sauer, S., Walach, H., and Kohls, N.: 'Gray's behavioural inhibition system as a mediator of mindfulness towards well-being', Personality and Individual Differences, 2011, 50, (4), pp. 506-511

[97] Peper, E., and Weijman, A.C.M.: 'De Computermens : Evolutie en preventie van RSI' (Elmar Publishers, 2003. 2003)

[98] Chiappetta, M.: 'The Technostress: definition, symptoms and risk prevention', Senses and Sciences, 2017, 4, (1), pp. 358-361

[99] Lundberg, U.: 'Stress hormones in health and illness: the roles of work and gender', Psychoneuroendocrinology, 2005, 30, (10), pp. 1017-1021

[100] van der Heijden, H.: 'USER ACCEPTANCE OF HEDONIC INFORMATION SYSTEMS', Mis Quarterly, 2004, 28, (4), pp. 695-704

[101] Thoits, P.A.: 'Stress and health: Major findings and policy implications', Journal of health and social behavior, 2010, 51, (1_suppl), pp. S41-S53

[102] Thoits, P.A.: 'Conceptual, methodological, and theoretical problems in studying social support as a buffer against life stress', Journal Of Health And Social Behavior, 1982, pp. 145-159

[103] Thoits, P.A.: 'Stress, coping, and social support processes: Where are we? What next?', Journal of health and social behavior, 1995 , pp. 53-79

[104] Taylor, S.E., and Stanton, A.L.: 'Coping resources, coping processes, and mental health', Annu. Rev. Clin. Psychol., 2007, 3, pp. 377-401

[105] Moqbel, M.: 'The Effect of the use of social networking sites in the workplace on job performance', Texas A\&M International University, 2012

[106] Moqbel, M., Nevo, S., and Kock, N.: 'Organizational members' use of social networking sites and job performance: An exploratory study', Information Technology \& People, 2013, 26, (3), pp. 240-264 [107] Lin, N., Woelfel, M.W., and Light, S.C.: 'The buffering effect of social support subsequent to an important life event', Journal of Health and Social Behavior, 1985, 26, (3), pp. 247-263

[108] Igbaria, M., Parasuraman, S., and Baroudi, J.J.: 'A Motivational Model of Microcomputer Usage', Journal Of Management Information Systems, 1996, 13, (1), pp. 127 143

[109] Kock, N., Moqbel, M., Barton, K., and Bartelt, V.: 'Intended continued use of social networking sites: effects on job satisfaction and performance', International Journal of Virtual Communities and Social Networking, 2016, 8, (2), pp. $28-46$

[110] Turel, O., Serenko, A., and Bontis, N.: 'User acceptance of hedonic digital artifacts: A theory of consumption values perspective', Information \& Management, 2010, 47, (1), pp. 53-59

[111] Lin, H.-H., Wang, Y.-S., and Chou, C.-H.: 'Hedonic and utilitarian motivations for physical game systems use behavior', International Journal of Human-Computer Interaction, 2012, 28, (7), pp. 445-455

[112] Carmody, J., Baer, R.A., LB Lykins, E., and Olendzki, N.: 'An empirical study of the mechanisms of mindfulness in a mindfulness-based stress reduction program', Journal of clinical psychology, 2009, 65, (6), pp. 613-626

[113] Akin, A.: 'Self-compassion and Loneliness', International Online Journal of Educational Sciences, 2010, 2, (3), pp. 702-718

[114] Bluth, K., and Blanton, P.W.: 'Mindfulness and selfcompassion: Exploring pathways to adolescent emotional well-being', Journal of child and family studies, 2014, 23, (7), pp. 1298-1309

[115] Sriwilai, K., and Charoensukmongkol, P.: 'Face it, don't Facebook it: impacts of social media addiction on mindfulness, coping strategies and the consequence on emotional exhaustion', Stress and Health, 2015,

Forthcoming

[116] Kimbrough, E., Magyari, T., Langenberg, P., Chesney, M., and Berman, B.: 'Mindfulness intervention for child abuse survivors', Journal of clinical psychology, 2010, 66, (1), pp. 17-33

[117] Ayyagari, R., Grover, V., and Purvis, R.:

'Technostress: Technological antecedents and implications', MIS Quarterly, 2011, 35, (4), pp. 831-858

[118] Moore, J.E.: 'One road to turnover: An examination of work exhaustion in technology professionals', MIS Quarterly, 2000, pp. 141-168

[119] Moriarty, D., Zack, M., and Kobau, R.: 'The centers for disease control and prevention's healthy days measures - population tracking of perceived physical and mental health over time', Health and Quality of Life Outcomes, 2003, 1, (37), pp. 1-8 